\title{
Obituary
}

\section{Dr C. N. H. Long}

HugH LoNG, the endocrinologist, and Sterling Professor Emeritus at Yale, died suddenly at Pennaquid Beach, Maine, on July 6, 1970, at the age of sixty-nine.

Born in Nettleton, England, he began his education in science at Manchester University in organic chemistry. After receiving his MSc in 1923, Long went with A. V. Hill to the Department of Physiology, University College, London, where he took part, with Hill and Lupton, in the work on the biochemistry of muscular exercise and fatigue in man, supported by the Industrial Fatigue Research Board.

In 1924 he was elected a member of the Physiological Society. That year, on appointment as lecturer in medical research, Long entered the Medical School at McGill and after receiving his MD in 1928 stayed on as a member of the Department of Medicine. With J. Beattie and G. R. Brow he studied the action of anaesthetics on skeletal muscle and on the heart, with results which led to the report that chloroform induces extra systoles by an action via the hypothalamus. These studies by Beattie, Brow and Long are among the last of the significant papers on hypothalamic physiology before the "stereotaxic era" was opened by S. W. Ranson and his associates.

In 1932 Dr Long was appointed director of the Cox Institute of Medical Research, a small endowed laboratory attached to the Department of Medicine at the University of Pennsylvania. Houssay and Biassotti had just discovered that hypophysectomy ameliorates the metabolic effects of pancreatectomy in toads and dogs. Two years later Long, with Lukens, an instructor in the Department of Medicine, reported that adrenalectomy also "alleviates" the diabetes of depancreatized cats, and suggested that this effect is brought about by the decreased production of glucose and ketone bodies rather than by restoration of glucose utilization. By selective operations they were able to attribute the alleviation of the diabetic condition to removal of adrenal cortex rather than medulla.

After his appointment in 1936 to the faculty of Yale University School of Medicine, on which he served until he retired in 1969, first as professor and chairman of the Department of Physiological Chemistry (1936-51), then as dean (1947-51) and later as professor of physiology (1951-69) and chairman of the department (1951-64), Long continued to focus his research interests on the adrenal gland. During the Second
World War, when he became a citizen of the United States, Long directed research in his department on the endocrine status and intermediary metabolism of animals subjected to haemorrhage, in the course of which a study was made of the action of ACTH in depletion of the cholesterol content of the adrenal cortex and later the depletion of ascorbic acid; this led to a standard test for adrenal cortical activation. Long was also interested in the possibility of a neural component in the activating system, and hypothesized that epinephrine might be the common denominator of the great variety of conditions known to stimulate the hypophysial-adrenal system. His last research, in collaboration with Ora Kingsley Smith, dealt with the endocrine status of the "visceral organism", a preparation developed under his direction by $T$. Hiroshige for perfusing the abdominal and thoracic viscera under conditions in which their metabolic interaction could be analysed.

Honorary degrees were conferred on Dr Long by Princeton, McGill and the University of Venezuela. He received the Banting Memorial Medal of the American Diabetes Association in 1951 and was a member of the National Academy of Sciences, the American Academy of Arts and Sciences and the Philosophical Society.

\section{Announcements}

\section{University News}

Dr H. D. Suit, University of Texas, has been appointed professor of radiation therapy and chief of the Department of Radiation Medicine at the Massachusetts General Hospital, Harvard University.

Dr Rainer Goldsmith has been appointed to the chair of physiology at Chelsea College of Science and Technology, University of London, and Dr J. A. S. Smith has been appointed to the chair of chemistry tenable at Queen Elizabeth College.

\section{Appointments}

Nathan M. Pusey, president of Harvard University, will succeed Charles $\mathbf{S}$. Hamilton as president of the Andrew W. Mellon Foundation.

Professor G. A. Barnard, University of Essex, Mr D. J. Barron, York University, and Professor W. G. McClelland, Man- chester Business School, have been appointed members of the Social Science Research Council.

Dr Melvin N. A. Peterson has been appointed co-principal investigator of the Deep Sea Drilling Project, which is managed by the Scripps Institution of Oceanography under contract to the US National Science Foundation. Dr N. Terence Edgar will succeed Dr Peterson as chief scientist of the project.

\section{Miscellaneous}

The CIBA medal and prize for 1970 has been awarded by the Biochemical Society to Professor D. C. Phillips, University of Oxford. The Colworth medal of the Society has been awarded to Dr D. A. Rees, Unilever Research Laboratory, and the Gowland Hopkins medal to Dr F. Sanger, MRC Laboratory of Molecular Biology.

The British Nutrition Foundation will present an award of $£ 1,000$ annually for the next five years to individual scientists for distinguished research in nutrition. The first recipient of the award, to be known as the British Nutrition Foundation prize, is Professor R. A. McCance, University of Cambridge.

Erratum. In the article "Kinetic Mass Spectrometric Study of the Flash Photolysis of $\mathrm{NO}_{2}$ " by J. N. Bradley, W. D. Capey and J. R. Gilbert (Nature, 229, $41 ; 1971)$, the following corrections should be made. The sentence beginning on line 10 of the first paragraph should read "The sampling nipple ..."; line 13 of paragraph 5 should read "... and this seems most unlikely $100 \mathrm{~ms}$ after flash"; the end of the penultimate sentence should read ". . . produces $\mathrm{NO}_{2}$ in the presence of NO (ref. 8)".

ERRATUM. In the article "Trials with a Transponding Acoustic Fish Tag tracked with an Electronic Sector Scanning Sonar" by $M$. Greer Walker, R. B. Mitson and T. Storeton West (Nature, $229,196 ; 1971)$, the last figure in the last column of Table 1 should be 1.46 . 